\title{
An Empirical Exploration of Bus Travel Times and Dwell Times in a Highly Competitive Exclusive Busway'
}

\author{
Daniel A. Rodriguez, University of North Carolina, Chapel Hill
} Arturo Ardila, Massachusetts Institute of Technology

\begin{abstract}
$\overline{\text { Abstract }}$
Busway transit has reemerged as a cost-effective transportation alternative for providing urban mobilit: This article examines the operational characteristics of an exclusive busway system with high passenger ridership and subject to the competitive forces of individual operators. Results of a running time model suggest that the increase in running time associated with an additional passenger movement is low but that the delay imposed by recurrent vehicle deceleration and acceleration related to frequent stops is high. Frequent vehcle stops reduce fuel efficiency; increase pollution, reduce travel time, and decrease productivity: Results of several specifications of divell-time regression models indicate that established models tend to yield biased coefficients for boarding and alighting passenger movements. These model results also confirm that the dwell-time delay associated with an additional passenger movement is very low in Bogotá's busway' even though average dwell time per passenger tends to be high. It follow's, therefore, that organizing passenger boarding and alighting operations and consolidating passenger activity points promise to be effective strategies for improving operations. More broadly; the findings indicate that under a deregulated operating environment, a regulatory framework that includes monitoring operations and enforcing designated stop locations remains important for efficient busway operations.
\end{abstract}




\section{Introduction}

Public transportation planners have begun to reconsider the usefulness of busways or bus rapid transit as cost-effective investments for satisfying growing demands for urban mobility. A busway is road space designated for exclusive use by buses and segregated to the maximum practical extent from other traffic. Even though they offer slightly lower passenger capacity than heavy rail. busways are attractive because they can be implemented incrementally and can accommodate dynamic budgetary and demand constraints more readily than fixed track systems.

Partly as a result of the relative cost advantage of busways, many developing cities now view them as a key mass transit alternative to consider. Accordingly, busways operating in heavily traveled urban corridors have become more common in cities in the developing and developed world such as Ankara, Brisbane, Ottawa, Miami, and São Paulo. Unlike corridor-specific busway lines, there are few busway transit networks in the world; the most notable is the system in Curitiba. Extensive networks also are under planning and implementation in Bogotá and Lima.

Notwithstanding the increasing appeal of busways, institutional arrangements for managing and providing transit service along busways have been poorly understood, even though these arrangements are particularly important for developing cities. Except for synopses of Brazil's leading experience in busway transit suggesting that a consistent regulatory framework improves busway productivity (e.g., Rebelo and Benvenuto 1997; Smith and Hensher 1998), the impact of different institutional arrangements on the operation of busways constitutes a gap in knowledge that is seldom acknowledged explicitly. Often the assumption is that busway transit should be provided by a public monopoly or by private operators under contract with a public agency. Thus. there is paucity of research regarding transit services on exclusive busways that are open to the highly competitive forces of hundreds of individual (private) operators. In many ways, regulated operations and unregulated competitive operations represent two opposite busway development trajectories available for many cities, particularly in the developing world. As such, developing our 
understanding about competitive transit operations in exclusive busways is useful for planners and decision-makers.

Numerous cases of highly competitive busway operators exist in Abidjan, Istanbul. Bogotá, São Paulo, and other areas. Furthermore, previous research (Ardila and Rodríguez 2000) suggests that very high passenger throughput is achievable under a competitive environment, but poor service quality prevails. In this context, the objective of the current study is to examine how the competitive environment and high passenger demand can affect the operation of busways. It investigates if low average speeds in competitive busways are a result of vehicle dwell time and thus are amenable to infrastrastructure or vehicle improvements, or if they are the result of vehicle crowding related to the current regulatory environment.

This article is the second part of a broader study whose goal is to examine the operations of highly competitive transit services in an exclusive busway in Bogotá. Colombia. The first study used vehicle load data and time-distance diagrams to examine passenger throughput and vehicle movements along the busway (Ardila and Rodriguez 2000). We found that by forming temporary platoons, vehicles are able to serve the high passenger demand albeit at low speeds. By using dwell time and running time models in the context of the existing regulatory environment, the primary objective of this article is to explore the impact of high ridership and the current regulatory environment on vehicle operations (e.g., speed, dwell time, number of stops). A secondary objective is to use the results of the models to propose specific interventions that can improve busway operations in the short term. Lessons learned from this analysis should be useful for cities having or considering busway transit as an option for improving urban accessibility and mobility.

Contrary to the literature, we find that the average boarding and alighting delay per passenger is unexpectedly high (5.6 seconds) in the Bogotá busway. At the same time, the marginal contribution of passenger boardings and alightings to dwell times is low when compared to similar systems elsewhere. We attribute these differences to the operating environment of the busway: passenger movements occur surprisingly quickly, and thus dwell 
times are a relatively low percentage of total running time. Instead of affecting vehicle dwell times per se, passenger movements affect running time through vehicle clearance maneuvers (deceleration and acceleration). As a result, organizing passenger charging and discharging operations promises to be an effective strategy to reduce running times and improve vehicle utilization. More broadly, we find that institutional factors remain critically important to sustaining the attribute that makes busways attractive-their design flexibility. This finding is relevant for cities with high busway ridership potential because it underscores the importance of alternative institutional arrangements that can support effective transit operations.

This article begins with a brief a description of the Bogotá busway. It presents empirical analyses of running times and dwell times and discusses their implications. The article concludes with a summary of findings and recommendations.

\section{Bogotá's Exclusive Busway: 1988-2001}

Bogotá's exclusive busway was built between 1988 and 1992 during three different city administrations (Acevedo 1996). Its development was animated by three key factors:

1. unfettered population and urban growth along the city's north-south axis, which resulted in increased trips lengths for the bus-dependent population;

2. relative cost advantage and design flexibility of busways over rail systems; and

3. success of busways in neighboring Brazil.

Accordingly, Bogotá planners designed a 16-km busway as part of a major arterial traversing the city's central business district (CBD) and connecting the south and north parts of town. With more than 200 routes with different origin and destinations, the busway effectively acts as a high-capacity collector fed by routes needing to cross the city rapidly. Passenger flows exceed 36,000 passengers per hour on a given direction during the peak period (Ardila and Rodriguez 
2000: Cal y Mayor Asociados 1999). Despite this extraordinary peak-passenger flow, average vehicle occupancy remains low in comparison with busways elsewhere (e.g., Abidjan, Pôrto Alegre (Brazil), São Paulo, Ankara).

The busway physically separates public transportation vehicles from mixed traffic by using small blocks ( $15 \mathrm{~cm}$ in height and width, and $30 \mathrm{~cm}$ in length) adhered to the pavement (Figure 1a). Four center lanes, two in each direction, are available exclusively to high-capacity (80-120 passengers) public transportation vehicles. Two external lanes in each direction are assigned to mixed traffic. Stations are located 500 meters apart from each other. Each station is 100 meters long, is raised 0.30 meters from the ground, contains four different sections labeled $A$ through $D$, and has limited passenger entry points (Figure $1 b$ ). In each section, in principle, only buses with a common destination can stop for passenger boarding and alighting.

Two types of public transportation vehicles are allowed on the busway: vehicles known locally as "corrientes" and the slightly more comfortable "intermedios." Although the city's bus fleet size encompasses many more bus and microbus classes, only these two types of vehicles are allowed on the busway due to their higher capacity and front and rear doors, which facilitate passenger movements. The distinction between the two bus types is tenuous and can mostly be attributed to the lower age and higher fares of intermedios. Buses tend to be full-size single-deckers built on truck chassis, most with front engines, manual shifting, and high entry steps. All vehicles have front doors for entry and rear doors for exit and are operated by a single driver. The driver or an assistant collects the fares.

Entry of operators during the past five years has resulted in low productivity levels, which has decreased profit margins and exacerbated fierce competitive behavior. The infrastructure itself is suffering from lack of maintenance. Bus stops tend to be in disrepair. Traffic lights are not synchronized and gridlock is common in several streets crossing the busway. Average vehicle speeds in 1999 were $24 \mathrm{kph}$ ( $15 \mathrm{mph}$ ), a low speed by international standards but a high one relative to the citywide average vehicle speed of $9 \mathrm{kph}(5.6 \mathrm{mph})$. 


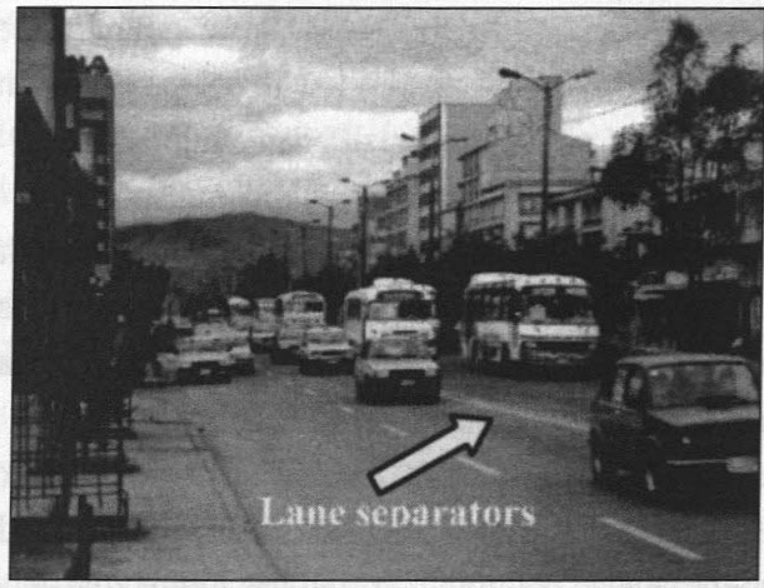

Figure 1a. Mixed traffic and exclusive busway lanes

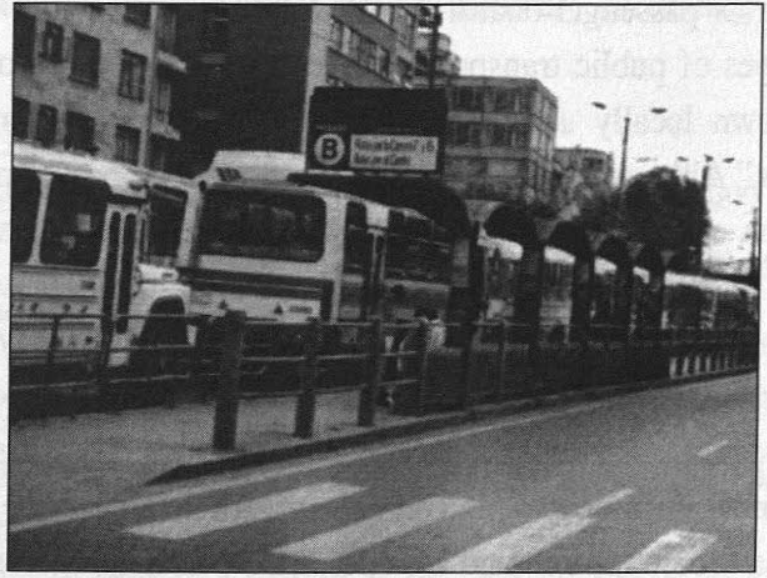

Figure $1 \mathrm{~b}$. Stops arranged by vehicle destination

\section{Empirical Analysis of Vehicle Running Times}

Running time is a key concept governing the operator's bottom line in areas such as vehicle utilization and labor cost. Furthermore, changes in running time can cause variations in headways, which induce variations in passenger waiting time. In the context of Bogotá's exclusive busway, the aim is to examine the extent to which passenger demand and the highly competitive environment affect vehicle running times. 
Under nonexclusive bus transit operating conditions, vehicle running time consists of six components:

\section{1. free-flow time;}

2. time spent negotiating traffic, including traffic lights and other vehicles;

3. time spent in clearance maneuvers to attend passengers demanding to board or alight the vehicle;

4. time spent on passenger movements, including fare payment, reaching the bus, and boarding and alighting (dwell time);

5. time spent in en-route control operations such as schedule adjustments; and

6. other delays specific to the vehicle and its driver.

Exclusive busways can impact the above items by specific design improvements such as segregating buses from mixed traffic and other transit vehicles, decreasing vehicle dwell times, moving fare collection activities off vehicles, and providing operational improvements (e.g., signal prioritization schemes).

Regression analysis can be used for relating vehicle running time to several of the above components and to highlight areas of improvement. Assuming that some of these factors cannot be incorporated into a statistical model for future prediction, they will be included in the error term of the regression equation. The larger the error term, the more significant are those factors that are not included explicitly among the independent variables.

Civil and environmental engineering undergraduate students at the Universidad de los Andes at Bogotá collected data as part of a course assignment to study transit data collection techniques and analysis. Twenty-three students, 12 in the morning peak and 11 in the evening peak, boarded two vehicles each along the entire busway. Although students were instructed to board vehicles every two minutes, this timing was difficult to maintain in practice. When first boarding a vehicle, each individual recorded the vehicle type (corriente or intermedio) and the number of on-board passengers. Thereafter, each data collector recorded the number of passengers boarding, alighting, and the 
current lane of the vehicle for each full stop made. Because vehicle doors tend to remain open throughout the entire trip, giving people the opportunity to board and alight wherever the vehicle is stopped, dwell time was measured as the time the vehicle remained stopped. Running-time and dwell-time information result from these data, with the expected caveat that observations for a given vehicle are not independent of each other. This nonindependence can arise if, for example, a specific driver systematically behaved in a way that influenced dwell times for that route.

A total of 46 trip times and 1,604 stops were observed. This means that vehicles stopped an average of 35 times. On average, 10 percent $( \pm 4 \%)$ of the running time is spent in passenger boarding and alighting operations. This percentage does not vary by direction or peak period. Using data from several city transit systems such as Boston, Philadelphia, and St. Louis, Levinson (1983) estimated that 26 percent of the trip time of buses serving a CBD was attributed to dwell times. Similarly, Levinson estimated that 20 percent and 12 percent of vehicle trip times were due to dwell times in non-CBD urban services and in suburban services, respectively. These comparisons suggest that despite high passenger volumes, average dwell times appear to be quite low for Bogotá's busway. Other descriptive summary statistics at the vehicle level are provided in Table 1.

\begin{tabular}{|llrrrrr|}
\hline & \multicolumn{5}{c}{$\begin{array}{c}\text { Table 1 } \\
\text { Vescriptive Statistics }\end{array}$} \\
\hline Variable Label & Description & Mean & Standard Deviation & Min & Max \\
\hline TIME & Running time (min) & 43.64 & 1234 & 21.25 & 68.12 \\
ONS & Passengers boarding & 34.53 & 18.38 & 1 & 81 \\
OFFS & Passengers alighting & 36.11 & 19.53 & 6 & 100 \\
STOPS & Number of stops made & 37.04 & 12.41 & 16 & 71 \\
TYPE & Vehicle type (1 = Corriente) & $23 \%$ & & & \\
\hline
\end{tabular}

Casual observations of the authors do suggest appreciable differences in the way users behave within the Bogotá busway in comparison to other bus systems in developed countries. For example, only sometimes do vehicles come to a full stop when a single person is boarding or alighting, a practice with questionable safety consequences. 
Under an operating scheme where full stops are not always made, we expect the total number of stops per vehicle trip or the cumulative number of passenger boardings per trip to have a considerable influence on total running time. Consequently, an ordinary least squares (OLS) linear regression with total running time per vehicle (in minutes) as dependent variable was estimated (Table 2). The variables ONS and OFFS are aggregated into a single variable $(A L L)$.

\begin{tabular}{|c|c|c|}
\hline \multicolumn{3}{|c|}{$\begin{array}{c}\text { Table } 2 \\
\text { Running Time Model Results }\end{array}$} \\
\hline Variable Label & Coefficient & Standard Error \\
\hline ALL (ONS + OFFS) & $0.18 *$ & 0.06 \\
\hline STOPS & $0.38^{*}$ & 0.13 \\
\hline TYPE & -4.55 & 2.98 \\
\hline CONSTANT & $18.09^{*}$ & 4.14 \\
\hline \multicolumn{3}{|c|}{$F(3,43)=17.18, P>000$} \\
\hline \multicolumn{3}{|c|}{ Adj. $\mathrm{R}^{2}=0513$} \\
\hline \multicolumn{3}{|c|}{ Dependent varable $=T I M E(\min )$} \\
\hline - Significant at a $99 \%$ & nce level. & \\
\hline
\end{tabular}

The results support the hypothesis that total passenger movements and vehicle stops are important factors influencing running time. The coefficients suggest that every stop increases running time by 22.8 seconds which includes the marginal deceleration and acceleration time effects of each additional vehicle stop. Type of vehicle is not statistically significant, while the constant is significant. The constant can be interpreted as the nonstop travel time that a vehicle would take to traverse the $16 \mathrm{~km}$ busway, resulting in an average speed of $53.1 \mathrm{kph}$. Finally, an additional passenger boarding or alighting increases running time by 0.18 minutes, or 11 seconds, which appears relatively high given that the delay effect of vehicle maneuvering is being accounted for. Dwell-time models may be useful for clarifying the nature of the relationship between passenger movements and vehicle delay. 


\section{Empirical Analysis of Dwell Times}

The contribution of passenger boardings and alightings to running times may only tell part of the story regarding the busway's operations. As a contributor to running time, vehicle dwell time is a widely recognized source of headway variation and thus of the number of passengers waiting to board a vehicle. Kraft and Deutschmann (1977) categorize the factors influencing dwell time as human. modal, operating policies, operating practices, mobility, climate, and other system elements. Some of these factors do not change within daily operations while others are not useful for forecasting purposes. Conventionally, the number of passenger boardings and alightings tends to be the best predictor of vehicle dwell time. Accordingly, the Transit Capacity and Quality of Service Manual (U.S. Department of Transportation 1999) suggests, "dwell time is proportional to the boarding and/or alighting volumes times the service time per passenger" (pp. 2-7).

Other dwell-time factors of interest include vehicle type, physical dimension and location of doors, and fare payment scheme. Researchers have developed different regression models that include boardings and alightings. Some have modeled dwell times separately (Guenthner 1988) while others have modeled them as a function of boardings and alightings simultaneously (Levine and Torng 1994; Lin-Ming and Wilson 1993). At least two studies have also included variables accounting for vehicle crowding (Lin-Ming and Wilson 1993: Zografos and Levinson 1986).

To examine dwell times with the current date, the unit of analysis shifts from the trip to the stop. A preliminary analysis of dwell times (Table 3) determined that they are correlated with passenger boarding and alightings. As the mean dwell time increases, the number of boardings and alightings also increases. To partially account for the correlation among observations, the variance of dwell time is decomposed as within bus route variance and between bus route variance.

\section{Classical Linear Regression and Dwell Time}

Based on theory, prior published research, and the preliminary results in Table 3, boardings and alightings were identified as the major factors influencing dwell times. Other factors that may also influence dwell times include interactions 


\begin{tabular}{|c|c|c|c|}
\hline \multicolumn{4}{|c|}{$\begin{array}{c}\text { Table } 3 \\
\text { Dwell Times by Boardings and Alightings }\end{array}$} \\
\hline Boardings and Allontming per Stop & $<3$ & $3-4$ & $>4$ \\
\hline Sample size & 1,258 & 253 & 93 \\
\hline Mean $A L L$ (ONS + OFFS) & 1.22 & 3.32 & 619 \\
\hline Mean passenger load & 35.40 & 40.10 & 3980 \\
\hline Mean dwell time (in seconds) & 8.61 & 11.26 & 19.12 \\
\hline Standard deviation dwell time & 9.59 & 9.45 & 13.67 \\
\hline Standard deviation between buses & 3.47 & 8.99 & 11.28 \\
\hline Standard deviation withın buses & 9.80 & 7.56 & 10.41 \\
\hline \multicolumn{4}{|c|}{ Total sample (number of stops sampled): 1,604} \\
\hline \multicolumn{4}{|c|}{ Overall mean dwell time (in seconds) $=9.64$} \\
\hline \multicolumn{4}{|l|}{ Median dwell tume (in seconds) $=6$} \\
\hline Standard deviation of dwell time $=10.2$ & & & \\
\hline
\end{tabular}

between passenger loads and boardings and alightings, presence of standing passengers. and vehicle stopping lanes (left or right lane). Results for several model specifications are given in Table 4. All standard errors reported are estimated using White's (1980) estimator of the variance-covariance matrix, which corrects for the heteroscedasticity introduced by the sampling design. The first two models correspond to the standard specification found in the literature (Levine and Torng 1994; Lin-Ming and Wilson 1993; U.S. Department of Transportation 1999). The main difference between the two specifications is that the second model includes dummy variables for the 46 vehicles observed (VEHICLE [i]) and thus capture vehicle and driver-specific factors that are regularly unaccounted for in dwell-time models. This addition increases the explanatory power of the model from a meager 9 percent to 17 percent.

Both models suggest that marginal passenger boardings take between 1.8 and 2.1 seconds and marginal passenger alightings between 1.1 and 1.6 seconds. The difference between boardings (ONS) and alighting (OFFS) is statistically significant in both models. Stopping in the passing lane ( $L E F T)$ increases marginal dwell time by about 4 seconds. This indicates that strict enforcement of stopping lane use can yield fruitful results in terms of lower dwell times and lower running times for both the vehicle in question and other vehicles behind it. In addition, passenger activity to and from a vehicle stopped in the left lane is inherently dangerous. 


\begin{tabular}{|c|c|c|c|c|c|c|c|}
\hline 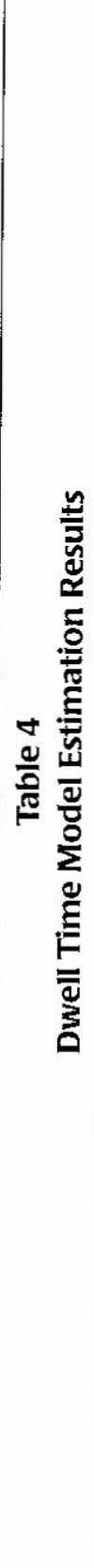 & 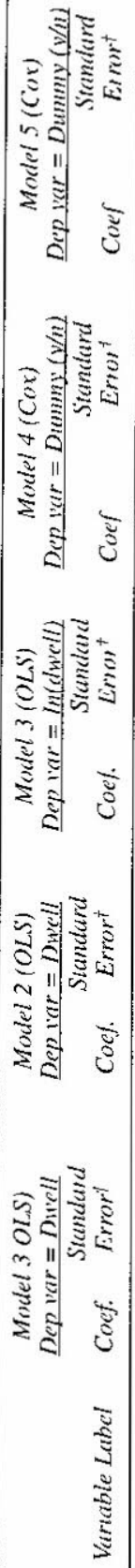 & 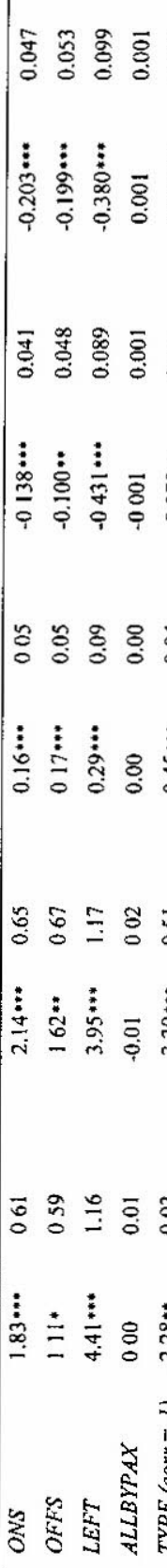 & 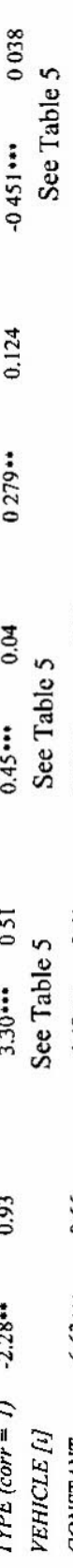 & 志 & 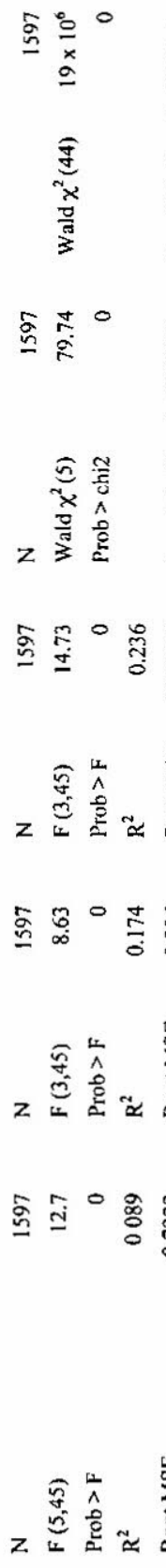 & 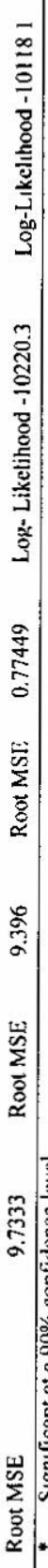 & 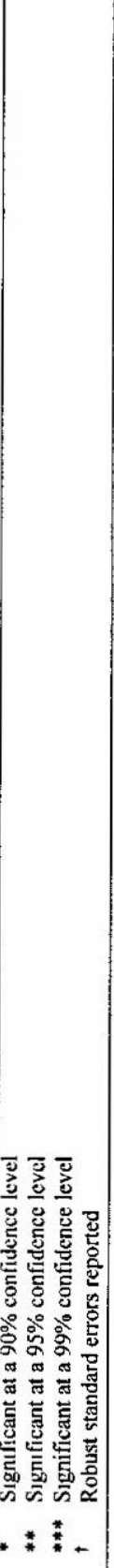 \\
\hline
\end{tabular}


Perhaps the largest difference between the estimated coefficients of model 1 and 2 is the change in sign of the vehicle-type variable. The change from negative to positive suggests an omitted variable bias in the first specification that resulted in the negative sign for TYPE. Once we controlled for individual drivers and vehicles, the results suggest the corriente vehicles have inherently higher dwell time than intermedios. These results are consistent with age, physical, and operating differences between the two types of vehicles described previously.

The main limitation of the first two model specifications is the assumption that dwell times are normally distributed, when in practice this assumption is often violated. Guenthner and Sinha (1983) suggest that boarding and alighting times are log-normally distributed. Even though the hypothesis that the distribution of boarding plus alighting times is lognormal can be rejected at a 99 percent confidence level for the current data, we specified a third logliner model. The dependent variable becomes the natural log of dwell time observed. All independent variables in model 2 are included in the third model, but direct comparisons across models are not possible. The third model's explanatory power is close to 25 percent and the same variables remain statistically significant as in the previous models. The marginal effect of passenger movements decreases to about 1.2 seconds per passenger and is statistically the same for passenger boardings and alightings.

\section{Time-to-Event Models and Dwell Times}

An alternative way to examine the impact of passenger movements on dwell times is to view them as a measure of time-to-departure at each stop. Under this approach, vehicles are defined as being in one of two states: dwelling or not dwelling. The event of interest is not dwell time per se but the transition of vehicles from a dwelling state to a nondwelling state. From this basic information we can estimate the probability that a vehicle in the sample will stop dwelling for each point in time and the factors that increase or decrease such probability.

This modeling approach is common in disciplines such as economics (duration modeling, see Kiefer 1988), engineering (reliability analysis), and 
the health sciences (survival analysis, see Klein and Moeschberger 1997). To our knowledge, this approach has not been used in the past to examine vehicle dwell times. The appeal of using time-to-event models is that the imposition of a parametric distribution on observed durations is not necessary, thereby circumventing some of the limitations of the models estimated before.

As with traditional linear regression, a valuable attribute of time-to-event models applied to dwell-time analysis is the ability to compare how the probability function of vehicle departure from each stop varies over time and under different operating circumstances, such as the number of passenger boardings and alightings, stopping lanes, and vehicle types. We operationalize the timeto-event model with Cox's hazards regression. Cox regression models the probability that each vehicle at each stop changes state as time passes without imposing a distribution on the duration of the event. It assumes a baseline risk or "hazard" common to all observations in the sample, which can be interpreted conceptually as the shared likelihood of departure at any point in time for all observations. Intuitively, this can be viewed as each vehicle's common probability of moving after the delay inherent in any dwelling maneuver.

Formally, a Cox model with $\mathrm{n}$ independent variables is written as:

$$
\lambda(t)=\lambda_{0}(t) e^{\beta_{1} X_{1}+\beta_{2} X_{2}+\ldots+\beta_{n} X_{n}}
$$

where:

$\lambda(t)$ is the baseline hazard.

$\beta_{1}$ is a set of coefficients estimated showing the effects of independent variable $i$ on the observation's hazard rate.

The Cox model also assumes that hazards are proportional in the sense that predictors influence the baseline hazard a constant multiplicative way. A positive coefficient increases the hazard function, meaning that the change of state will occur sooner than otherwise. A negative coefficient reduces the hazard function. which means that the dwell duration is longer. Thus, contrary to linear regression, estimated coefficients for number of passengers boarding or alighting are expected to have a negative sign, meaning that they decrease the probability of departure, thereby increasing dwell time. Additional details about the Cox model and other survival models can be found in Klein and Moeschberger (1997). 
Models 4 and 5 (Table 4) contain the results for two Cox model specifications. As before, the first specification does not include dummy variables for each vehicle type, whereas Model 5 does include those variables. The same variables as in the classical linear regression models remain significant and have the expected signs. The change in sign of the vehicle-type variable confirms the omitted variable bias of Model 4. Furthermore, a likelihood ratio test between models 4 and 5 indicates that the latter has better fit $(\mathrm{P}>0.00)$.

The coefficients in Model 5 suggest that for every additional passenger boarding or alighting, the risk of ending the stopped state decreases by 20 percent. A less rigorous but more intuitive interpretation would be that an additional passenger increases dwell times an average of 20 percent. Evaluated at the median dwell time of 6 seconds, this translates to a delay of 1.2 seconds per passenger, which is the same delay calculated in Model 3. Also consistent with the third model, the marginal impacts of passenger boardings and alightings on dwell times remain the same. This is a somewhat puzzling result given that passengers need to pay the fare when boarding a vehicle, but it illustrates that regression model specifications prevalent in dwell-time studies (Models 1 and 2) may be biased.

\section{Implications of Dwell-Time Modeling Results}

A comparison of the five dwell-time regression models shows that different assumptions about the distribution of dwell times yields quite different results. For example, estimates of the marginal effects of passenger boardings and alightings using classical linear regression models tended to be consistently higher than results using other distributional assumptions. This difference is important when evaluating the impact of proposed investments or alternative operating strategies. In both cases inclusion of variables capturing vehicle and driver factors improved model fit and corrected estimates that would have been biased otherwise. More broadly, the results suggest that by using a hazards regression approach there are gains in accuracy and theoretical soundness but also there are significant losses in model interpretability. The consistency between the hazards model and the loglinear model results suggests that the latter represents a good compromise for researchers and agencies investigating vehicle dwell times. 


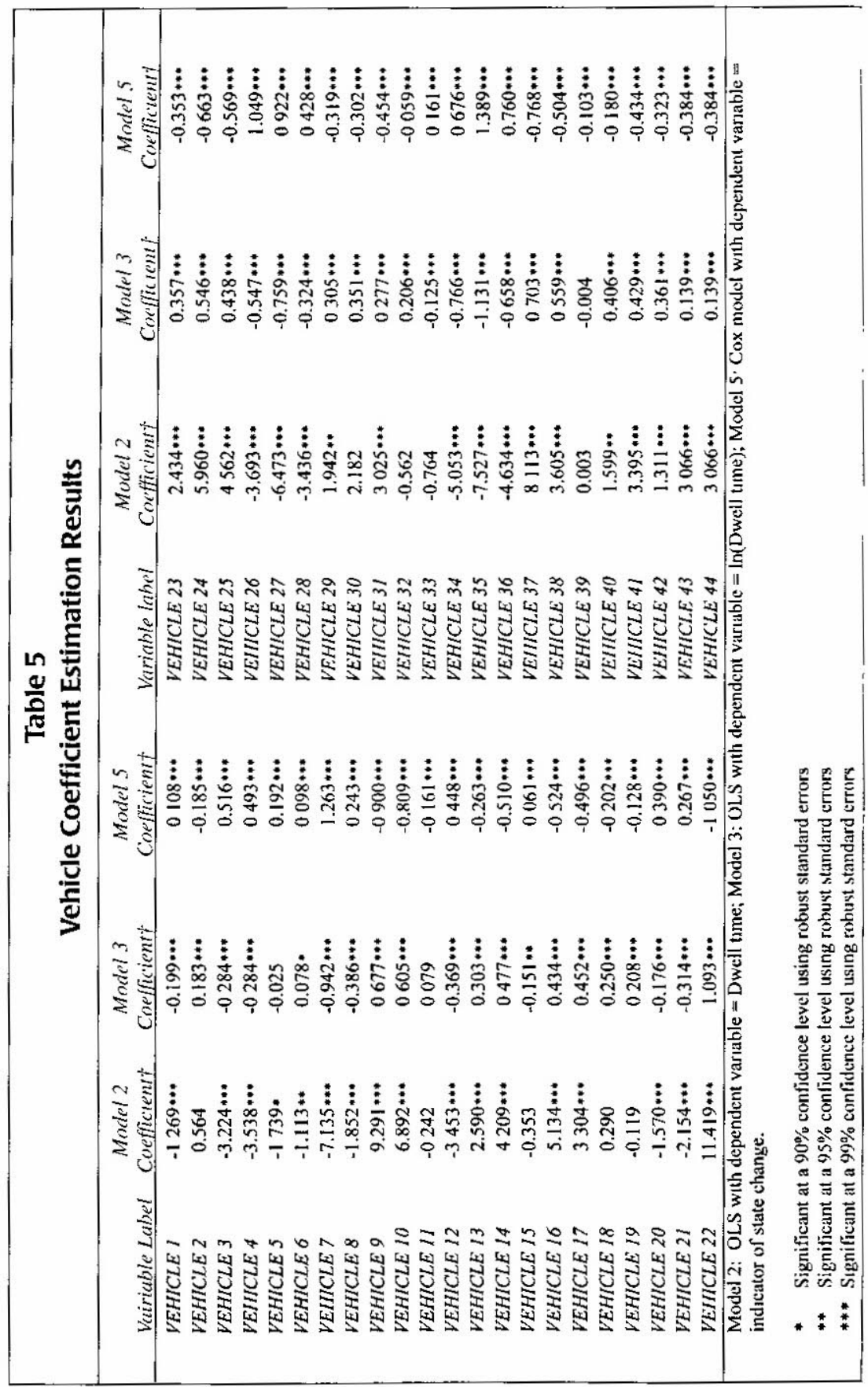


Overall, the explanatory power of models estimated here is lower than the explanatory power of linear regression models in other studies, which tend to explain between 35 percent (Guenthner and Sinha 1983) and 77 percent (Levine and Torng 1994) of the variance of the dependent variable. Our results suggest that factors other than the ones specified in the models influence dwell time. Furthermore, the fact that dwell-time models have a low explanatory power despite using independent variables that have had good model fit in a more organized transit scenario is telling of the chaotic and unreliable operating scheme that persists.

A comparison of the dwell-time models estimated with similar models for other transit systems in developed cities (Kraft 1975; Kraft and Eng-Wong 1977; Levinson 1982; Levinson 1983) suggests that marginal boarding times for Bogotá s busway are quite low. The busway's boarding times are 70 percent lower than marginal boarding times estimated for London or Dublin, 50 percent lower than Singapore and Hong Kong, and 20 to 35 percent lower than marginal times estimated for Boston and New Haven. Perhaps a better comparison is to consider cities that operate under similarly high competitive conditions and in which vehicle boardings are exclusively supervised by the driver. In the busways in Ankara and Istanbul, under varying fare payment arrangements, marginal passenger dwell times tend to be 33 percent higher than in Bogotá's (Gardener et al. 1991).

Contrary to prevailing research (Kraft and Deutschmann 1977; Levine and Torng 1994; Lin-Ming and Wilson 1993), the effect of passenger crowding is statistically insignificant in every model. Other studies indicated that adding crowding variables to reflect on-board congestion significantly improves the explanatory powers of most models, but that is not the case here. An immediate explanation can be the low average occupancy due to the oversupply of capacity.

In sum, the model results consistently show that dwell times, both cumulative and marginal, are lower than those for other busways elsewhere. This clarifies results from the running time model that suggested a relevant association between passenger movements and total running time. The results indicate that factors other than passenger movements and vehicle and driver-specific factors 
are important determinants of vehicle dwell times and running times. Taken together, our results support the view that the de-facto unregulated operating environment has deleterious effects on the cost efficiency and service effectiveness of the busway as defined by Fielding (1987) despite the impressive ridership that often surpasses that of many subways in the world. However, the extent to which poor institutional oversight is reflected on the competitive behavior of individual operators vis-à-vis other operational aspects such as poor signal coordination and cross-traffic blockages remains to be determined.

\section{Conclusions}

Much remains to be learned about alternative institutional and operating arrangements for the provision of high-quality transit service. Despite being an attractive option for many cities, there is paucity of research regarding transit services on exclusive busways. In particular, busways open to the highly competitive forces of hundreds of individual (private) operators have not been examined in the past.

From a technical perspective, this article sheds light on improving the estimation and usefulness of statistical models for transit operations. First, conventional dwell-time models appear to inflate the marginal importance of passenger boardings and alightings. A hazards regression model, although theoretically appealing, is far from useful in day-to-day transit planning practice. A log-linear model appears to be an adequate compromise. Second, the presence of factors influencing dwell times and running times unrelated to driver, vehicle, and demand factors limit the usefulness of established statistical models for planning purposes in similar busway scenarios. Given the competitive nature of the Bogotá busway, this is not surprising and can suggest that interaction among vehicles can be as important to explaining running times as conventional data.

The findings of this article suggest that passenger demand has a tangible influence on vehicle running times. However, this influence does not materialize via high vehicle dwell times, as expected. Instead, the marginal delay related to vehicle maneuvers is a key contributor to total running time. Recurrent stops imply vehicle deceleration and acceleration that reduce fuel efficiency, increase pollution, and affect passenger travel time and fleet utilization. This 
illustrates the trade-off that exists between the delay imposed by the number of stops and the delay associated with vehicle dwell times. As the number of stops arailable decreases, higher numbers of passengers per stop are expected to board and alight vehicles, thereby decreasing maneuvering delays but increasing per-stop dwell time. As a result, in a highly competitive environment where passenger throughput is a prime concern, planners and administrators are advised to improve the busway's operations by addressing the number and location of vehicle stops.

Paradoxically, the current infrastructure of the busway does reflect planners' attention to passenger movements. It contains clearly specified bus stop locations and. within each stop, vehicles should be organized according to their destination. However. lack of oversight or enforcement by city authorities coupled with the competitive environment has led to the misuse of these facilities. Vehicles often stop haphazardly throughout the busway and passengers do not respect designated route loading and unloading points. This suggests that a key attribute of busw ays, their flexibility to adapt to local conditions successfully, remains heavily dependent on institutional factors. The findings support the broader conclusion that under a deregulated operating environment a coherent regulatory framework is important for improving the efficiency of exclusive busways.

\section{Acknowledgments}

We are grateful to Nigel H. M. Wilson for his valuable feedback and suggestions, to anonymous reviewers, and to the students of civil and environmental engineering at Universidad de los Andes in Bogotá for their assistance in collecting the data.

\section{Endnote}

1. As this paper was being completed, the first phase of a revamped network of busways in Bogotá, TransMilenio, was inaugurated. The city of Bogotá improved the existing busway infrastructure and developed a tendering or concession process involving existing operators but organized into single firms. Preliminary ridership figures suggest that ridership has not changed along the corridor examined in this article but that travel times and overall level of service have improved considerably. 


\section{References}

Acevedo, J. 1996. La Troncal de la Caracas: Experiencia de una vía exclusiva para buses en Santa Fé de Bogotá. Paper presented at 8th Latin-American Congress of Public and Urban Transport, Curitiba (Brazil).

Ardila, A., and D. Rodriguez. 2000. How chaos does not destroy ridership: Operations of an exclusive busway carrying more than 35,000 passenger per hour per direction. Transportation Research Record 1726:1-8.

Cal y Mayor Asociados. 1999. Update of Demand Study for the Integrated Public Transportation System for Santa Fé de Bogotá. Bogotá: National Planning Department.

Fielding, G. 1987. Managing public transit strategically. London: Jossey-Bass.

Gardener, G. P., P. Cornwell, and J. Cracknell. 1991. The performance of busway transit in development cities. Transport and Road Research Laboratory.

Guenthner, R. P., and K. C. Sinha. 1983. Modelling bus delays due to passenger boardings and alightings. Transportation Research Record 915:7-13.

Guenthner, R. P. 1988. Transit dwell time under complex fare structure. Journal of Transportation Engineering 114:367-379.

Japan International Cooperation Agency-Chodai Co. Ltd. 1996. Estudio del plan maestro del transporte urbano de Santa Fé de Bogotá en la República de Colombia. Instituto de Desarrollo Urbano.

Kiefer, N. 1988. Economic duration data and hazard functions. Journal of Economic Literature 26:646-679.

Klein, J. P., and M. L. Moeschberger. 1997. Survival analysis: Techniques for censored and truncated data. Springer-Verlag.

Kozel, V. 1981. Travel demand models for developing countries. Washington. DC: The World Bank. 
Kraft. W.H. 1975. An analysis of the passenger vehicle interface of street transit systems with applications to design optimization. Doctoral dissertation. New Jersey Institute of Technology, Newark, NJ.

Kraft. W.H., and H. Deutschmann. 1977. Bus passenger service-time distributions. Transportation Research Record 625:37-43.

Kraft. W. H., and P. Eng-Wong. 1977. Passenger service time characteristics of street transit systems. Paper read at Institute of Transportation Engineers, 47th Annual Meeting, October 2-6, Mexico City.

Levine, J. C.. and G.-W. Torng. 1994. Dwell time effects of the low floor bus design. Journal of Transportation Engineering 120(6):914-929.

Levinson, H. S. 1982. INET transit travel times analysis. Washington, DC: Urban Mass Transportation Administration.

Levinson, H. S. 1983. Analyzing travel time performance. Transportation Research Record 915:1-6.

Lin-Ming, L., and N. H. M. Wilson. 1993. Dwell time relationships for light rail systems. Transportation Research Record 1361:287-295.

Rebelo, J., and P. Benvenuto. 1997. Lessons from São Paulo's metropolitan busway concessions program. Washington, DC: The World Bank.

Smith. N., and D. Hensher. 1998. The future of exclusive busways: The Brazilian experience. Transport Review's 18 (2):131-152.

U.S. Department of Transportation. 1999. Transit capacity and quality of service manual. Washington, DC.

White, H. 1980. A heteroscedasticity-consistent covariance matrix estimator and a direct test for heteroscedasticity. Econometrica 48:817-830.

Zografos, K. G. , and Levinson H. 1986. Passenger service times for a no-fare bus system. Transportation Research Record 1051:42-48. 


\section{About the Authors}

DANIEL RoDRíguez (danrod@unc.edu) is an assistant professor of transportation and land-use planning at the University of North Carolina at Chapel Hill. His primary research interests include understanding local and regional accessibility related to public transportation. Dr. Rodríguez received his Ph.D. in urban, technological, and environmental planning from the University of Michigan.

ARTuRo ARdila (aardila@mit.edu) is a doctoral candidate at the Massachusetts Institute of Technology. His primary research interest is on the relationship between politics and the planning of large transportation projects. 